\title{
Global Genome Nucleotide Excision Repair Proteins Rhp7p and Rhp41p Are Involved in Abasic Site Repair of Schizosaccharomyces pombe
}

\author{
Eiji Sakurai, Miyuki Susuki, Kyoichiro Kanamitsu, Shinji Kawano, Shogo Ikeda* \\ Department of Biochemistry, Faculty of Science, Okayama University of Science, Okayama, Japan \\ Email: ${ }^{*}$ ikeda@dbc.ous.ac.jp
}

Received 12 March 2015; accepted 3 April 2015; published 10 April 2015

Copyright (C) 2015 by authors and Scientific Research Publishing Inc.

This work is licensed under the Creative Commons Attribution International License (CC BY).

http://creativecommons.org/licenses/by/4.0/

\section{(c) (i) Open Access}

\section{Abstract}

The roles of nucleotide excision repair (NER) proteins in removing UV-induced lesions are well defined. There are two distinct NER pathways: global genome NER (GG-NER) and transcriptioncoupled NER. In human GG-NER, two heteromeric protein complexes, DDB1-DDB2 and XPC-RAD23, are responsible for initial lesion recognition. Here, we examined the genetic interactions between GG-NER and base excision repair (BER) genes during abasic (AP) site repair of Schizosaccharomyces pombe. Mutants of rhp7 (rhp7-rhp16 are functional homologs of DDB1-DDB2) and rhp41 (XPC homolog) were moderately sensitive to methyl methanesulfonate and slightly to sodium bisulfite. Nth1p most actively cleaves the AP site in $S$. pombe. Deletion of $r h p 7$ or rhp41 from nth1 cells greatly increased their sensitivity to alkylation and deamination, indicating that $R h p 7 p$ and Rhp41p are involved in repair of the AP sites generated by the action of DNA glycosylase. Induction of $r h p 7$ and $r h p 16$ genes by different types of DNA damage supports the ability of GG-NER to remove non-bulky lesions. Therefore, GG-NER activity not only targets bulky DNA helix-distorting lesions, but can also efficiently remove AP sites synergistically with BER.

\section{Keywords}

AP Site, Base Excision Repair, Global Genome Repair, Nucleotide Excision Repair, Schizosaccharomyces pombe

\footnotetext{
${ }^{*}$ Corresponding author.
}

How to cite this paper: Sakurai, E., Susuki, M., Kanamitsu, K., Kawano, S. and Ikeda, S. (2015) Global Genome Nucleotide Excision Repair Proteins Rhp7p and Rhp41p Are Involved in Abasic Site Repair of Schizosaccharomyces pombe. Advances in Bioscience and Biotechnology, 6, 265-274. http://dx.doi.org/10.4236/abb.2015.64026 


\section{Introduction}

Abasic (AP) sites are one of the most common DNA lesions and can be generated by the spontaneous hydrolysis of the sugar base glycosidic linkage or by the action of monofunctional DNA glycosylases, removing damaged bases formed by deamination, oxidation and alkylation (reviewed in reference [1]). AP sites are potent blocks to replicative DNA polymerases, and translesion synthesis (TLS) for the AP-site bypass by specialized TLS DNA polymerases leads to high mutagenicity [2] [3]. RNA polymerase II can also be blocked at AP sites in the transcribed strand in vitro [4]. In many organisms, base excision repair (BER) is the major pathway for the repair of AP sites, and is initiated by cleavage of the phosphodiester bond either by AP endonuclease or the AP lyase activity of bifunctional DNA glycosylase [5] [6]. AP endonuclease hydrolyzes the 5' side of the AP site leaving a 3'-hydroxyl group and a 5'-deoxyribose phosphate. AP lyase cleaves 3' to the AP site leaving a 3'- $\alpha, \beta$-unsaturated aldehyde (3' block) and a 5'-phosphate. Following incision of the DNA backbone, 5'- or 3'-blocked ends are removed to allow repair DNA synthesis and ligation of the remaining nick. Although BER is an evolutionarily conserved process, a fission yeast Schizosaccharomyces pombe has some unique features of the pathway. AP sites are incised mainly by AP lyase activity of Nth1p, a sole bifunctional glycosylase in the yeast, and the major AP endonuclease Apn2p functions predominantly in removing the 3' block (Nth1p-dependent BER) [7][9].

Nucleotide excision repair (NER) is a versatile DNA repair pathway that removes a broad spectrum of DNA lesions that tend to distort the double helix, and is well known for its role in the repair of UV-induced cyclobutane pyrimidine dimers (CPD) and 6-4 pyrimidine-pyrimidone photoproducts (6-4PP) [1] [10] [11]. There are two distinct subpathways of NER: global genome NER (GG-NER) and transcription-coupled NER (TC-NER). GG-NER can repair lesions throughout the genome while TC-NER is specialized to correct lesions from the transcribed strand of active genes. In human GG-NER, the DDB1-DDB2 and XPC-RAD23B heteromeric protein complexes are responsible for initial lesion recognition, whereas the CSA and CSB proteins initiate the onset of TC-NER. Although the $S$. pombe NER pathway has not been extensively investigated, in the initial step of GG-NER, the Rhp7p-Rhp16p complex (functional homolog of human DDB1-DDB2) detects UV photolesions throughout the genome and transfers the lesion site to the Rhp41p-Rhp23p complex (XPC-RAD23B homolog) [12] [13]. The Saccharomyces cerevisiae $R A D 7$ and $R A D 16$ genes, homologs of $r h p 7$ and rhp16, respectively, are essential for GG-NER [14] [15]. Rad7p and Rad16p forms a protein complex with Abf1p and mediates UVinduced histone H3 acetylation which results in chromatin remodeling required for efficient GG-NER [16] [17]. S. pombe has two homologs of the human XPC, Rhp41p and Rhp42p; Rhp41p plays a major role in removing CPD in the transcribed and non-transcribed strands [18] [19]. S. pombe Rhp26p, a homolog of human CSB and budding yeast Rad26p, likely plays a key role in TC-NER [20] [21].

Although BER and NER are generally considered to remove different types of lesions, the disruption of both pathways of $S$. cerevisiae displays synergistic effects on damage sensitivity and genome stability in yeast cells, indicating a functional overlap between the two pathways [22]-[25]. S. pombe contains two paralogues of 3methyladenine (3-meA) DNA glycosylase (Mag1p and Mag2p), and deficiency in both activities resulted in only a slight increase in sensitivity to methyl methanesulfonate (MMS), suggesting that Mag1p/Mag2p-initiated BER plays a minor role in repairing alkylation damage in yeast [26]-[28]. In contrast, S. pombe NER mutants rad13A, rad16 $\Delta$, and swi10 $\Delta$ display substantial sensitivity to MMS [26] [28]-[30]. These genes encode structure-specific endonucleases required for dual incision of the damaged DNA strand, which is critical for both GG-NER and TC-NER. Further disruption of the BER gene (mag1/mag2, nth1, or rad2) from these NER mutants increases the spontaneous intrachromosomal recombinant frequency and sensitivity to MMS, suggesting the synergistic roles of BER and NER on repairing spontaneous and exogenous alkylation damage [26] [28]-[30]. Recently, we have shown that the rhp41and rhp26 mutants exhibited sensitivity to MMS to the same extent as the rad16 strain [31]. Genetic interactions of rhp41and rhp26 with BER genes showed the involvement of Rhp41p and Rhp26p in the TC-NER of MMS-damaged DNA. Given that the alkylated bases such as 3-meA are immediately removed to generate AP sites in BER-proficient cells, the function of NER is considered to be redundant in AP site repair, when considered with BER. In this study, we examined genetic interactions between NER and BER genes during repair of alkylation and deamination damage. The results showed that Rhp7p and Rhp41p, which generally function in early steps of GG-NER of UV photolesions, are involved in repairing AP sites generated by the action of DNA glycosylase. 


\section{Materials and Methods}

\subsection{Construction of Strains}

Yeast strains used in this study are listed in Table 1. The $\operatorname{rhp} 7 \Delta$ strain was provided by NBRP of MEXT, Japan. Double and triple mutants were constructed by targeted disruption of the NER gene rhp7 and rhp41 in BERdefective strains mag $1 \Delta / \operatorname{mag} 2 \Delta$, nth1 $\Delta$, and apn2 $\Delta$ using a kanMX6 marker [32]. The rhp7::kanMX6 disruption cassette was prepared as follows. The genomic sequence of $r h p 7$ was amplified with the following primers: 5'TCTCAAGGTATCAATGCTTCAGCAT-3' and 5'-TTATTGAACTTCACGCCCTATCAGA-3'. The gene fragment was then subcloned into pGEM-T vector (Promega, Fitchburg, Wisconsin, USA) by TA cloning. The kanMX6 marker was amplified from pFA6a-kanMX6 [32] by PCR and inserted between HpaI and KpnI sites of rhp7 cloned in pGEM-T. The rhp7::kanMX6 disruption cassette was amplified by PCR and used to transform the $n t h 1 \Delta$ strain with lithium acetate [28]. The G418-resistant colonies were screened for the correct integration of kanMX6 marker within the rhp7 locus by PCR. The rhp41::kanMX6 disruption cassette was prepared as previously described [31].

\subsection{Survival Assay}

Cells were grown overnight in YEA medium (0.5\% yeast extract, $3 \%$ glucose, and $60 \mu \mathrm{g} / \mathrm{mL}$ adenine) for survival assays. Cell density was determined by a Z1 particle counter (Beckman Coulter, Brea, CA, USA), and adjusted to $1.0 \times 10^{7}$ cells $/ \mathrm{mL}$ with sterilized water. The cells were diluted 10 -fold serially from $10^{-1}$ to $10^{-3}$ in sterilized water. To measure the sensitivity of cells to chronic exposure to DNA damaging agents, dilutents ( $3 \mu \mathrm{L}$ ) containing $3 \times 10^{1}$ to $3 \times 10^{4}$ cells were spotted onto YE medium containing MMS (Sigma-Aldrich, St. Louis, MO, USA) or sodium bisulfite $\left(\mathrm{NaHSO}_{3}\right.$ ), and incubated for 3 days at $28^{\circ} \mathrm{C}$. For the UV sensitivity test, serial dilutions were spotted onto YE medium, and irradiated with 254-nm UV light using a UV crosslinker (FS-1500; Funakoshi Inc., Tokyo, Japan) equipped with an internal photodetector for measuring the UV dose. Photographs of colonies were taken after 3 days of growth at $28^{\circ} \mathrm{C}$.

\subsection{Gene Expression Analysis by Reverse Transcription (RT)-PCR}

Wild-type (WT) cells were cultured in YEA medium at $28^{\circ} \mathrm{C}$ until the optical density at $600 \mathrm{~nm}$ reached $\sim 1.0$. The cells were washed once with phosphate buffered saline (PBS), and resuspended in PBS at a cell density of $2.0 \times 10^{7}$ cells/mL. A 10-mL portion of the cell suspension was poured into a 9-cm petri dish, and UV was irradiated at various dosages. When cells were exposed to MMS, the agent was added to the cell suspension at various concentrations. After incubation at $28^{\circ} \mathrm{C}$ for $20 \mathrm{~min}$, MMS was neutralized with sodium thiosulfate. Damaged cells were washed once with YEA medium and incubated in medium at $28^{\circ} \mathrm{C}$ for 45 min with shaking. To extract total RNA, cells from the $10-\mathrm{mL}$ culture were washed once with $10 \mathrm{mM}$ Tris- $\mathrm{HCl}(\mathrm{pH} 8.0)$ and $1 \mathrm{mM}$ EDTA, and resuspended in $0.2 \mathrm{~mL}$ of a buffer containing $1 \mathrm{M}$ sorbitol, $0.1 \mathrm{M}$ EDTA, $14 \mathrm{mM}$ 2-mercaptoethanol,

Table 1. Strains used in this work.

\begin{tabular}{|c|c|c|}
\hline Strains & Genotypes & Source \\
\hline ED0665 & $h^{-}$ade6-M210 leu1-32 ura4-D18 & ATCC No. 96993 \\
\hline FY18796 & $h^{-}$ade6-M387 ura4-D18 rhp7::kanMX6 & $\mathrm{YGRC}^{\mathrm{a}}$ \\
\hline KK05 & $h^{+}$ade6-M216 leu1-32 ura4-D18 rhp41::kanMX6 & {$[31]$} \\
\hline KK01 & $h^{-}$ade6-M210 leu1-32 ura4-D18 rad16::kanMX6 & {$[28]$} \\
\hline HT02 & $h^{-}$leu1-32 ura4-D18 mag1::ura4 ${ }^{+}$mag2::ura4 ${ }^{+}$ & {$[28]$} \\
\hline MS02 & $h^{-}$leu1-32 ura4-D18 mag1::ura4 ${ }^{+}$mag2::ura4 $^{+}$rhp7::kanMX6 & This study \\
\hline TS01 & $h^{-}$ade6-M210 leu1-32 ura4-D18 nth1::ura4 ${ }^{+}$ & {$[8]$} \\
\hline ES01 & $h^{-}$ade6-M210 leu1-32 ura4-D18 nth1::ura4 ${ }^{+}$rhp7::kanMX6 & This study \\
\hline ES02 & $h^{-}$ade6-M210 leu1-32 ura4-D18 nth1::ura4 ${ }^{+}$rhp41::kanMX6 & This study \\
\hline AY01 & $h^{-}$ade6-M210 leu1-32 ura4-D18 apn2::ura4 ${ }^{+}$ & {$[8]$} \\
\hline ES01 & $h^{-}$ade6-M210 leu1-32 ura4-D18 apn2::ura4 ${ }^{+}$rhp7::kanMX6 & This study \\
\hline ST01 & $h^{-}$ade6-M210 leu1-32 ura4-D18 apn2::ura4 ${ }^{+}$rhp41::kanMX6 & This study \\
\hline
\end{tabular}

${ }^{a}$ YGRC: Yeast Genetic Resource Center. 
and 4000 units $/ \mathrm{mL}$ Zymolyase-20T. After incubation at $30^{\circ} \mathrm{C}$ for $30 \mathrm{~min}$, total RNA was isolated using a reagent, ISOGEN II (Wako Pure Chemical Industries, Osaka, Japan), according to the manufacturer's instructions. RNAs were dissolved in RNase-free water, and treated with an amplification grade DNase I (Sigma-Aldrich). cDNA was prepared using a High Capacity cDNA Reverse Transcription Kit (Applied Biosystems, Foster City, CA, USA) with an oligo(dT) $)_{16}$ primer. The target cDNA was amplified with GoTaq Green Master Mix (Promega) using the following gene-specific primer sets for rhp7 (5'-GCAGGATCAAGTTTTACACTTTTATGCGG ATC-3' and 5'-GGGCAACAGTCAACTATAGCGTTGATAAC-3'), for rhp16 (5'-GTTGTTGCTCCGGTTGT AGCAATTATGCA-3' and 5'-CCTTGATTTGATACCATGGGCCTCATCAA-3'), and for actin gene act1 (5'-GCACCTGCCTTTTATGTTGCTATTCAAGC-3' and 5'-GTTGGAAAAGAGCTTCAGGGGCACG-3'). Cycle parameters were: denaturation, $94^{\circ} \mathrm{C}$ for $1 \mathrm{~min}$; primer annealing, $51^{\circ} \mathrm{C}$ for $1 \mathrm{~min}$; extension, $72^{\circ} \mathrm{C}$ for 20 sec with a first denaturation time of $5 \mathrm{~min}$. Samples were electrophoresed on $2 \%$ agarose gels containing Gel Red Nucleic Acid Gel Stains (Biotium, Hayward, CA, USA) after 25 cycles of PCR. All cDNA samples were normalized to the expression of act1.

\subsection{Promoter Analysis}

An rhp16 promoter-lacZ fusion plasmid was constructed by PCR amplifying a DNA fragment corresponding to positions -2185 to 958 (relative to the ATG start codon) using primers rhp16BamHI (5'-CTTGGATCCTGATTCGGAGATCCATTCG-3') and rhp16PstI (5'-AACTGCAGAATGGGTTCTTTCATGTGATGG-3'). The resulting product was digested with BamHI and PstI before being ligated into the BamHI and PstI sites of pSPE356 [33] to yield pSPE356-rhp16(-2185/958). The plasmid was introduced into WT ED0665 strain using the $S$. pombe Direct Transformation Kit (Wako). The cells harboring the reporter plasmid were cultured in SD medium (0.67\% Difco yeast nitrogen base w/o amino acids, 3\% glucose, $60 \mu \mathrm{g} / \mathrm{mL}$ adenine and $40 \mu \mathrm{g} / \mathrm{mL}$ leucine) at $28^{\circ} \mathrm{C}$ until the optical density at $600 \mathrm{~nm}$ reached $\sim 1.0$. The cells were washed once with PBS, and resuspended in PBS at a cell density of $1.0 \times 10^{7}$ cells $/ \mathrm{mL}$. A 10 -mL aliquot of the cell suspension was poured into a 9-cm petri dish, and the cells were irradiated with UV. When the cells were exposed to DNA-damaging agents, MMS or $\mathrm{H}_{2} \mathrm{O}_{2}$ was added in cell suspension at appropriate concentrations and the cells were incubated at $28^{\circ} \mathrm{C}$ with shaking. The damaged cells were washed once with SD medium and incubated in medium at $28^{\circ} \mathrm{C}$ for $4 \mathrm{~h}$ with shaking. $\beta$-galactosidase activity in cells was measured by a liquid culture assay using $o$-nitrophenyl- $\beta$-D-galactoside (ONPG) as substrate according to the user manual of Clontech Laboratories, Inc. (Yeast Protocol Handbook PT3024-1).

\section{Results}

\subsection{Different Sensitivities of NER-Deficient Strains to UV and MMS Damage}

UV and MMS sensitivities of $r h p 7 \Delta$ and $r h p 41 \Delta$ strains were compared to those of the WT strain and a NER endonuclease-deficient mutant rad16 $\Delta$ (Figure 1). All NER mutants showed different levels of UV-sensitivity, even though $S$. pombe also uses an alternative mechanism, the Uve1p pathway, to remove UV damage [34]. Consistent with the literature [12] [19] [31], $r h p 41 \Delta$ and $r h p 7 \Delta$ were less sensitive to UV irradiation than rad16 , indicating that Rhp7p and Rhp41p are responsible for repairing some UV-induced lesions. rhp $7 \Delta$ exhi-

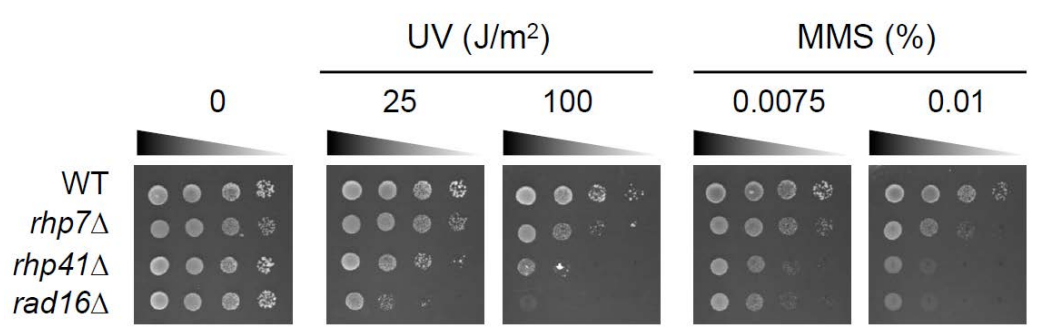

Figure 1. Sensitivity of various NER mutant strains to UV and MMS. WT cells

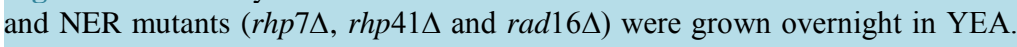
Survival assays for UV and MMS were carried out as described in the Materials and Methods. 
bited mild UV sensitivity among the NER mutants tested in this study. Although MMS damage is mainly repaired via the BER pathway in many organisms, several S. pombe NER mutants, including rad $16 \Delta$ and rhp41 $\Delta$, have been shown to display hypersensitivity to MMS [26] [30] [31]. rhp7 $\Delta$ was also sensitive to chronic exposure to MMS, indicating the contribution of Rhp7p to repair MMS-induced damage. rhp41 $\Delta$ exhibited similar MMS sensitivity to $\operatorname{rad} 16 \Delta$, and $r h p 7 \Delta$ was more weakly sensitive to MMS. These results suggest that GG-NER proteins Rhp7p and Rhp41p are responsible, to different degrees, for the correction of MMS-induced DNA lesions.

\subsection{Genetic Interactions of $r h p 7$ and $r h p 41$ with BER Genes during the Repair of Alkylated DNA}

To study the genetic interactions between NER and BER genes during the repair of MMS-damaged DNA, double and triple mutants were generated for epistasis analysis. A harmful lesion 3-meA is removed by the DNA glycosylases Mag1p and Mag2p to initiate the BER pathway [27] [28]. Although a previous study demonstrated the synergistic interaction between $r h p 41$ and $\mathrm{mag} 1 / \mathrm{mag} 2$ genes [31], a triple mutant mag1 $\Delta / \mathrm{mag} 2 \Delta / \mathrm{rhp} 7 \Delta$ exhibited the same sensitivity to MMS as the mag1 $\Delta / \operatorname{mag} 2 \Delta$ mutant (Figure 2(a)). These results indicate the contribution of Rhp41p, but not Rph7p, to correct 3-meA synergistically with Mag1p/Mag2p-initiated BER. Cytotoxic intermediates such as the AP site and the 3'-blocked end are generated during the BER of MMS-induced damage. In S. pombe, AP sites and 3'-blocked ends are thought to accumulate in the BER-deficient mutants $n t h 1 \Delta$ and apn2 2 , respectively [9] [35]. Deletion of the $r h p 7$ or $r h p 41$ gene from the $n$th $1 \Delta$ mutant greatly increased the sensitivity to MMS (Figure 2(b)), indicating that Rhp7p and Rhp41p are involved inrepair of the AP site synergistically with Nth1p. However, a synergistic interaction was not observed between apn2 $\Delta$ and NER mutants (Figure 2(c)). Thus, these NER proteins are unlikely to be responsible for repair of the 3'-blocked end.

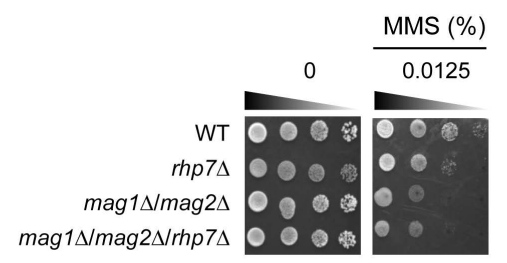

(a)

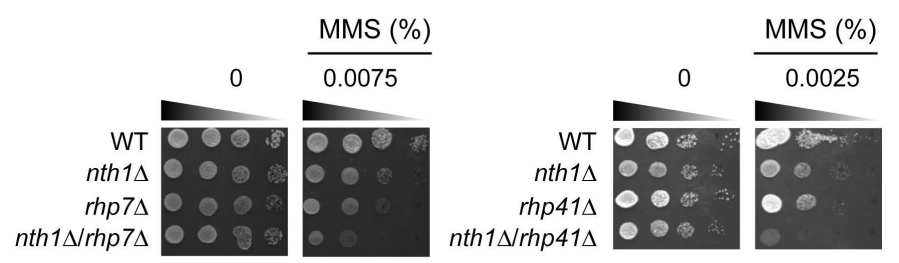

(b)

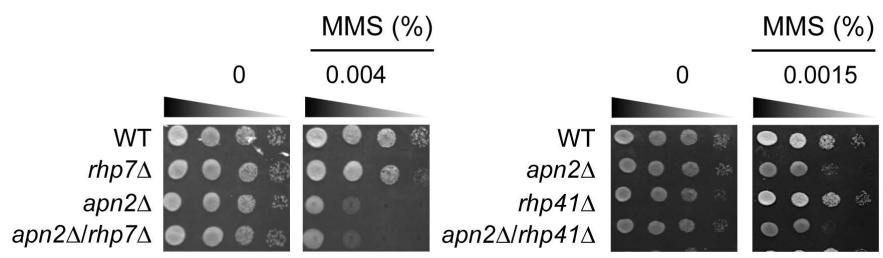

(c)

Figure 2. Genetic interactions among BER and NER genes during repair of MMS-induced damage. WT cells and various mutants were grown overnight in YEA. (a) Genetic interaction of $r h p 7$ with mag1/ mag2. (b) Genetic interactions of rhp7 and rhp41 with $n$ th1. (c) Genetic interactions of $r h p 7$ and rhp41 with apn2. Survival assays for MMS at various concentrations were carried out as described in the Materials and Methods, and culture plates that clearly show the difference of viability of each strain were photographed. 


\subsection{Genetic Interactions among BER and NER Genes during Repair of Sodium Bisulfite-Induced Damage}

Sodium bisulfite $\left(\mathrm{NaHSO}_{3}\right.$ ) promotes the deamination of cytosine to uracil [36]. In S. pombe, the resultant uracil can be removed by a uracil DNA glycosylase Ung1p to initiate the BER mechanism [37] [38]. Although an ung $1 \Delta$ mutant showed sensitivity to sodium bisulfite at the same level as the parental cells [38], the $n t h 1 \Delta$ mutant was slightly sensitive probably due to the accumulation of uracil-derived AP sites (Figure 3). The rhp41 $\Delta$ and $r h p 7 \Delta$ strains also displayed weak sensitivity to deamination. Double mutants $r h p 7 \Delta / n t h 1 \Delta$ and $r h p 41 \Delta$ $n t h 1 \Delta$ were more sensitive to sodium bisulfite than the corresponding single mutants, indicating a synergistic role of Rhp7p and Rhp41p to repair the AP site with Nth1p.

\subsection{Gene Induction of $r h p 7$ and $r h p 16$ by DNA Damage}

Rhp7p and Rhp16p form a protein complex and function in GG-NER [12]. Surprisingly, rhp7 and rhp16 genes are located very close together in a head-to-head orientation [12]. The expression of these genes in response to DNA damage was examined by quantitative RT-PCR using WT cells. Consistent with the literature [12], both $r h p 7$ and $r h p 16$ were significantly increased by UV irradiation $\left(>50 \mathrm{~J} / \mathrm{m}^{2}\right)$, although these genes were expressed at low levels under normal conditions (Figure 4(a)). Moreover, treatment with MMS at a high dose also led to a slight induction of these NER genes. DNA damage-dependent induction of these genes was further examined by a reporter assay using $r h p 7$ and rhp16 promoter-LacZ fusion plasmids. The S. pombe data base (PomBase) shows that the transcription initiation site of each gene is mapped within the coding region of the opposite gene and that an rhp16 antisense ncRNA is located just at the upstream region of the rhp7 gene, implying the complicated regulation of $r h p 7$ and $r h p 16$ gene expression (Figure 4(b)). Although several fragments were tested as the promoter for $r h p 7$ transcription, gene induction by UV irradiation was not observed (data not shown). On the other hand, reporter activity of the rhp16 promoter $(-2185 / 958)$ was induced about 4 -fold by UV irradiation, and also weakly induced by MMS and hydrogen peroxide (Figure 4(c)). These results indicate that $r h p 7$ and rhp16 are independently regulated and that the rhp16 promoter is inducible by different types of DNA damage.

\section{Discussion}

NER is thought to be a versatile DNA repair pathway that removes bulky lesions that disrupt or distort the DNA double helix, such as CPD and (6-4)PP [1] [10] [11]. Recently, evidence has accumulated which shows that NER or NER proteins play significant roles in the repair of nonbulky lesions, such as the AP site and subtle base modifications, produced by oxidative and alkylating damage in mammalian and lower eukaryotic cells [9] [11] [13] [25] [39]. Here, we provide genetic evidence that GG-NER proteins Rhp7p and Rhp41p are involved in repairing AP sites synergistically with BER in S. pombe cells.

The mammalian XPC protein plays a key role in DNA damage recognition and the subsequent initiation of GG-NER [10]. Helix-distorting lesions are recognized by the XPC complex and repaired via GG-NER. On the other hand, XPC appears to be also involved in BER by interacting with various DNA glycosylases. XPCHR23B functionally interacts with thymine DNA glycosylase (TDG) [40] and 3-meA DNA glycosylase [41] that facilitate BER of deamination and alkylation products, respectively. Although the XPC protein can recog-

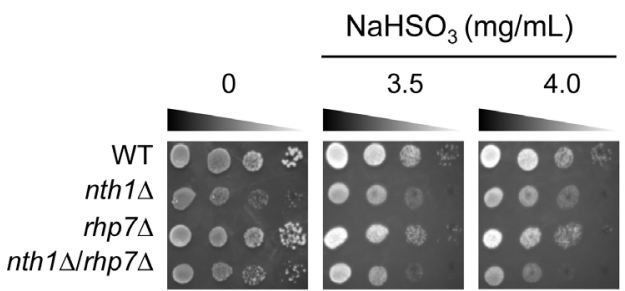

(a)

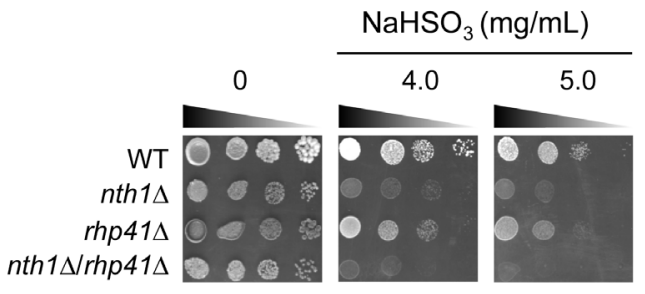

(b)

Figure 3. Genetic interactions among BER and NER genes during repair of $\mathrm{NaHSO}_{3}$-induced damage. WT cells and various mutants were grown overnight in YEA. (a) Genetic interactions of rhp7 with nth1. (b) Genetic interactions of rhp41 with $n$ th1. Survival assays for $\mathrm{NaHSO}_{3}$ were carried out as described in the Materials and Methods. 


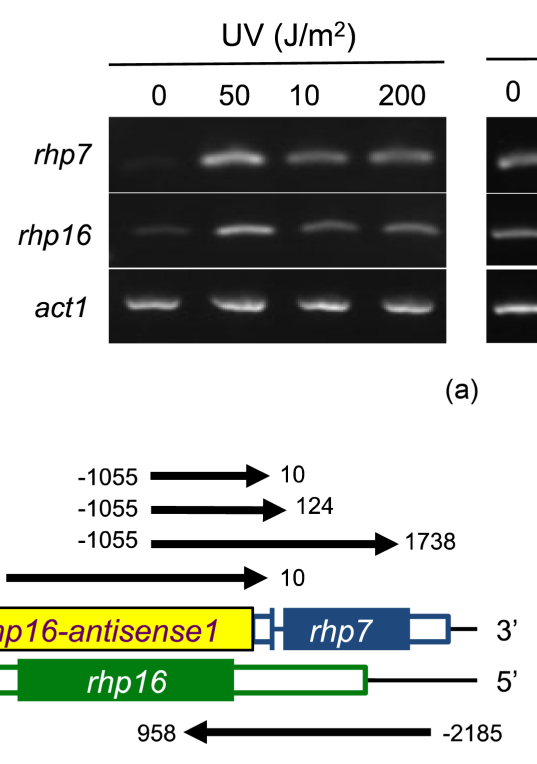

(b)
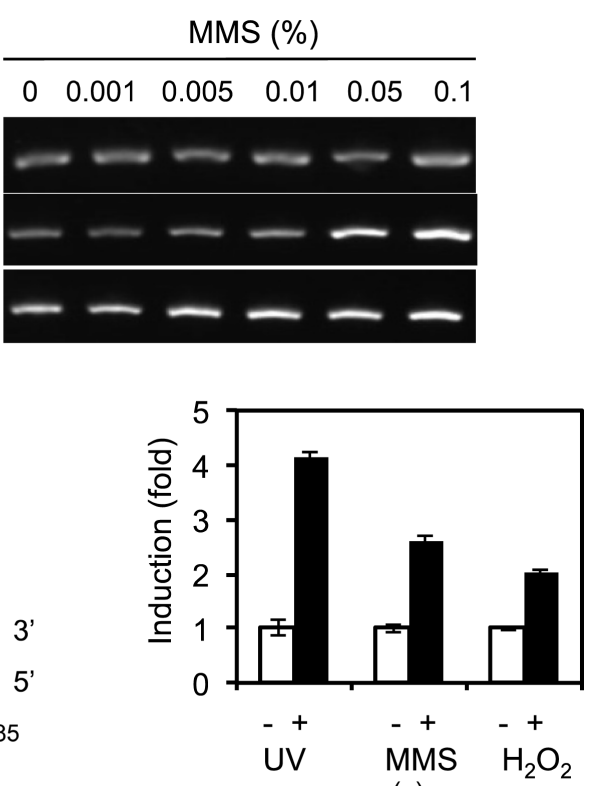

(c)

\begin{abstract}
Figure 4. DNA-damage dependent gene induction of rhp7 and rhp16. (a) WT cells were exposed to UV irradiation (left panel) or MMS (right panel) at various doses indicated in panels, and then incubated at $28^{\circ} \mathrm{C}$ for $20 \mathrm{~min}$. Extraction of total RNA and cDNA synthesis were carried out as described in the Materials and Methods. The expression of $r h p 7$ and $r h p 16$ gene was measured by PCR. All cDNA samples were normalized to the expression of act1. (b) Gene structure of $r h p 7$ and $r h p 16$ was illustrated with reference to the PomBase database (http://www.pombase.org). Four arrows over the map show the region used in the reporter assay for the $r h p 7$ promoter. Arrow under the map shows the region used for the $r h p 16$ promoter. Numbers on both sides of the arrows indicate the nucleotide number (relative to the ATG start codon of each gene) of the promoter fragments. (c) Induction of rhp16 promoter activity by UV irradiation and chemical treatments. WT cells carrying the rhp 16 promoter-lacZ reporter were cultured at $28^{\circ} \mathrm{C}$ in $\mathrm{SD}$ medium until the cells proliferated exponentially. After damaging the cells, they were harvested and processed for liquid $\beta$-galactosidase assays. Results are the mean values (relative activity) \pm SD for three experiments.
\end{abstract}

nize and directly bind to AP sites, a protein-protein interaction seems to be important for the stimulation of DNA glycosylases by XPC, rather than competition for AP sites [42]. We showed that Rhp41p synergistically functions with Nth1p in repairing DNA alkylation and deamination in S. pombe cells (Figure 2 and Figure 3). Because elimination of the rad16 gene encoding NER endonuclease from $n$th $1 \Delta$ cells also displays an additive effect on sensitivity to MMS [31], Rhp41p possibly interacts with AP sites and leads to repair of the lesion via NER, rather than BER. In S. cerevisiae, NER competes with the actions of two AP endonucleases Apn1p and Apn2p in the removal of AP sites [24]. The potential competence of NER to target AP sites has been supported by an in vitro excision assay using a human cell-free extract [43].

The Rhp7p-Rhp16p complex has been demonstrated to be essential for GG-NER of UV photolesions by repair analyses with a nucleotide resolution [12]. Although no structural homologs of Rhp7p and Rhp16p have been identified in mammals, the Rhp7p-Rhp16p complex appears to share some striking functional similarities with DDB1-DDB2. A defect in $r h p 7$ increased sensitivity to different types of alkylating agents, MMS and $N$ methyl- $N$ '-nitro- $N$-nitrosoguanidine (Figure 1) [13]. In S. pombe, an alkyltransferase-like protein (Atl1p) has the ability to bind DNA containing $O^{6}$-methylguanine, and to protect against the deleterious effect of DNA alkylation damage by downstream recruitment of NER [13] [44]. In this case, the Rhp7p complex facilitates Rhp41p binding via an interaction with the Atl1p-lesion complex, possibly involving chromatin remodeling or displacement of Atl1p [13]. Here, we demonstrated an additive genetic interaction between $r h p 7$ and $n t h 1$ during repair of DNA alkylation and deamination, indicating that the Rhp7p-Rhp16p complex is involved in repair of the AP site generated by the action of DNA glycosylase (Figure 2 and Figure 3). Induction of $r h p 7$ and $r h p 16$ genes by different types of DNA damage will support the ability to remove non-bulky lesions via GG-NER 
(Figure 4). The human DDB1-DDB2 complex recognizes AP sites and mismatches as well as CPD and 6-4PP, although there are no reports on the function of DDB1-DDB2 in either BER or the mismatch repair pathway [45].

AP site repair is also accomplished by TC-NER, which is triggered when RNA polymerase II stalls at the lesion. Recent results showed that deletion of S. pombe rhp26 (CSB homolog) in the nth1 $\Delta$ strain greatly enhanced MMS sensitivity, suggesting that the AP site could be corrected by TC-NER [31]. In S. cerevisiae, the uracilderived AP sites on the transcribed strand are also efficiently removed via TC-NER [25]. Therefore, both GGand TC-NER activities not only target to bulky DNA helix-distorting lesions, but can also effectively remove AP sites and subtle base modifications.

\section{Conclusion}

We investigated the genetic interactions between NER and BER genes during repair of alkylation and deamination damage. Deletion of the rhp7 or rhp41 gene from the nth1 mutant increased the sensitivity to MMS and $\mathrm{NaHSO}_{3}$, indicating that GG-NER proteins Rhp7p and Rhp41p are involved in repair of the AP sites generated by the action of DNA glycosylase. Furthermore, induction of rhp7 and rhp16 genes by different types of DNA damage supports the ability of GG-NER to remove non-bulky lesions. Therefore, GG-NER activity not only targets bulky DNA helix-distorting lesions, but can also efficiently remove AP sites synergistically with BER.

\section{Acknowledgements}

This work was supported in part by JSPS KAKENHI Grant Number 25340039. The authors would like to thank to Mr. S. Tatsume at Okayama University of Science, for construction of mutants and survival assays.

\section{References}

[1] Friedberg, E.C., Walker, G.C., Siede, W., Wood, R.D., Schultz, R.A. and Ellenberger, T. (2006) DNA Repair and Mutagenesis. 2nd Edition, ASM Press, Washington DC.

[2] Hubscher, U., Maga, G. and Spadari, S. (2002) Eukaryotic DNA Polymerases. Annual Review of Biochemistry, 71, 133-163. http://dx.doi.org/10.1146/annurev.biochem.71.090501.150041

[3] Goodman, M.F. (2002) Error-Prone Repair DNA Polymerases in Prokaryotes and Eukaryotes. Annual Review of Biochemistry, 71, 17-50. http://dx.doi.org/10.1146/annurev.biochem.71.083101.124707

[4] Tornaletti, S., Maeda, L.S. and Hanawalt, P.C. (2006) Transcription Arrest at an Abasic Site in the Transcribed Strand of Template DNA. Chemical Research in Toxicology, 19, 1215-1220. http://dx.doi.org/10.1021/tx060103g

[5] Hegde, M.L., Hazra, T.K. and Mitra, S. (2008) Early Steps in the DNA Base Excision/Single-Strand Interruption Repair Pathway in Mammalian Cells. Cell Research, 18, 27-47. http://dx.doi.org/10.1038/cr.2008.8

[6] Robertson, A.B., Klungland, A., Rognes, T. and Leiros, I. (2009) Base Excision Repair: The Long and Short of It. Cellular and Molecular Life Sciences, 66, 981-993.

[7] Alseth, I., Korvald, H., Osman, F., Seeberg, E. and Bjørås, M. (2004) A General Role of the DNA Glycosylase Nth1 in the Abasic Sites Cleavage Step of Base Excision Repair in Schizosaccharomyces pombe. Nucleic Acids Research, 32, 5119-5125. http://dx.doi.org/10.1093/nar/gkh851

[8] Sugimoto, T., Igawa, E., Tanihigashi, H., Matsubara, M., Ide, H. and Ikeda, S. (2005) Roles of Base Excision Repair Enzymes Nth1p and Apn2p from Schizosaccharomyces pombe in Processing Alkylation and Oxidative DNA Damage. DNA Repair, 4, 1270-1280. http://dx.doi.org/10.1016/j.dnarep.2005.06.009

[9] Kanamitsu, K. and Ikeda, S. (2010) Early Steps in the DNA Base Excision Repair Pathway of a Fission Yeast Schizosaccharomyces pombe. Journal of Nucleic Acids, 2010, Article ID: 450926, 9 pages.

[10] Naegeli, H. and Sugasawa, K. (2011) The Xeroderma Pigmentosum Pathway: Decision Tree Analysis of DNA Quality. DNA Repair, 10, 673-683. http://dx.doi.org/10.1016/j.dnarep.2011.04.019

[11] Melis, J.P., van Steeg, H. and Luijten, M. (2013) Oxidative DNA Damage and Nucleotide Excision Repair. Antioxidants \& Redox Signaling, 18, 2409-2419. http://dx.doi.org/10.1089/ars.2012.5036

[12] Lombaerts, M., Peltola, P.H., Visse, R., den Dulk, H., Brandsma, J.A. and Brouwer, J. (1999) Characterization of the $r h p 7^{+}$and $r h p 16^{+}$Genes in Schizosaccharomyces pombe. Nucleic Acids Research, 27, 3410-3416. http://dx.doi.org/10.1093/nar/27.17.3410

[13] Latypov, V.F., Tubbs, J.L., Watson, A.J., Marriott, A.S., McGown, G., Thorncroft, M., Wilkinson, O.J., Senthong, P., Butt, A., Arvai, A.S., Millington, C.L., Povey, A.C., Williams, D.M., Santibanez-Koref, M.F., Tainer, J.A. and Margi- 
son, G.P. (2012) Atl1 Regulates Choice between Global Genome and Transcription-Coupled Repair of $O^{6}$-Alkylguanines. Molecular Cell, 47, 50-60. http://dx.doi.org/10.1016/j.molcel.2012.04.028

[14] Verhage, R., Zeeman, A.M., de Groot, N., Gleig, F., Bang, D.D., van de Putte, P. and Brouwer, J. (1994) The RAD7 and RAD16 Genes, Which Are Essential for Pyrimidine Dimer Removal from the Silent Mating Type Loci, Are Also Required for Repair of the Nontranscribed Strand of an Active Gene in Saccharomyces cerevisiae. Molecular and Cellular Biology, 14, 6135-6142. http://dx.doi.org/10.1128/MCB.14.9.6135

[15] Reed, S.H., Akiyama, M., Stillman, B. and Friedberg, E.C. (1999) Yeast Autonomously Replicating Sequence Binding Factor Is Involved in Nucleotide Excision Repair. Genes \& Development, 13, 3052-3058. http://dx.doi.org/10.1101/gad.13.23.3052

[16] Teng, Y., Liu, H., Gill, H.W., Yu, Y., Waters, R. and Reed, S.H. (2008) Saccharomyces cerevisiae Rad16 Mediates Ultraviolet-Dependent Histone H3 Acetylation Required for Efficient Global Genome Nucleotide-Excision Repair. EMBO Reports, 9, 97-102. http://dx.doi.org/10.1038/sj.embor.7401112

[17] Waters, R., Evans, K., Bennett, M., Yu, S. and Reed, S. (2012) Nucleotide Excision Repair in Cellular Chromatin: Studies with Yeast from Nucleotide to Gene to Genome. International Journal of Molecular Sciences, 13, 11141-11164. http://dx.doi.org/10.3390/ijms130911141

[18] Fukumoto, Y., Hiyama, H., Yokoi, M., Nakaseko, Y., Yanagida, M. and Hanaoka, F. (2002) Two Budding Yeast $R A D 4$ Homologs in Fission Yeast Play Different Roles in the Repair of UV-Induced DNA Damage. DNA Repair, 1, 833-845. http://dx.doi.org/10.1016/S1568-7864(02)00108-8

[19] Marti, T.M., Kunz, C. and Fleck, O. (2003) Repair of Damaged and Mismatched DNA by the XPC Homologues Rhp41 and Rhp42 of Fission Yeast. Genetics, 164, 457-467.

[20] Yasuhira, S., Morimyo, M. and Yasui, A. (1999) Transcription Dependence and the Roles of Two Excision Repair Pathways for UV Damage in Fission Yeast Schizosaccharomyces pombe. The Journal of Biological Chemistry, 274, 26822-26827. http://dx.doi.org/10.1074/jbc.274.38.26822

[21] Wang, L., Limbo, O., Fei, J., Chen, L., Kim, B., Luo, J., Chong, J., Conaway, R.C., Conaway, J.W., Ranish, J.A., Kadonaga, J.T., Russell, P. and Wang, D. (2014) Regulation of the Rhp26 ${ }^{\mathrm{ERCC} 6 / \mathrm{CSB}}$ Chromatin Remodeler by a Novel Conserved Leucine Latch Motif. Proceedings of the National Academy of Sciences of the United States of America, 111, 18566-18571. http://dx.doi.org/10.1073/pnas.1420227112

[22] Xiao, W. and Chow, B.L. (1998) Synergism between Yeast Nucleotide and Base Excision Repair Pathways in the Protection against DNA Methylation Damage. Current Genetics, 33, 92-99. http://dx.doi.org/10.1007/s002940050313

[23] Swanson, R.L., Morey, N.J., Doetsch, P.W. and Jinks-Robertson, S. (1999) Overlapping Specificities of Base Excision Repair, Nucleotide Excision Repair, Recombination, and Translesion Synthesis Pathways for DNA Base Damage in Saccharomyces cerevisiae. Molecular and Cellular Biology, 19, 2929-2935.

[24] Torres-Ramos, C.A., Johnson, R.E., Prakash, L. and Prakash, S. (2000) Evidence for the Involvement of Nucleotide Excision Repair in the Removal of Abasic Sites in Yeast. Molecular and Cellular Biology, 20, 3522-3528. http://dx.doi.org/10.1128/MCB.20.10.3522-3528.2000

[25] Kim, N. and Jinks-Robertson, S. (2010) Abasic Sites in the Transcribed Strand of Yeast DNA Are Removed by Transcription-Coupled Nucleotide Excision Repair. Molecular and Cellular Biology, 30, 3206-3215. http://dx.doi.org/10.1128/MCB.00308-10

[26] Memisoglu, A. and Samson, L. (2000) Contribution of Base Excision Repair, Nucleotide Excision Repair, and DNA Recombination to Alkylation Resistance of the Fission Yeast Schizosaccharomyces pombe. Journal of Bacteriology, 182, 2104-2112. http://dx.doi.org/10.1128/JB.182.8.2104-2112.2000

[27] Alseth, I., Osman, F., Korvald, H., Tsaneva, I., Whitby, M.C., Seeberg, E. and Bjørås, M. (2005) Biochemical Characterization and DNA Repair Pathway Interactions of Mag1-Mediated Base Excision Repair in Schizosaccharomyces pombe. Nucleic Acids Research, 33, 1123-1131. http://dx.doi.org/10.1093/nar/gki259

[28] Kanamitsu, K., Tanihigashi, H., Tanita, Y., Inatani, S. and Ikeda, S. (2007) Involvement of 3-Methyladenine DNA Glycosylases Mag1p and Mag2p in Base Excision Repair of Methyl Methanesulfonate-Damaged DNA in the Fission Yeast Schizosaccharomyces pombe. Genes \& Genetic Systems, 82, 489-494. http://dx.doi.org/10.1266/ggs.82.489

[29] Kunz, C. and Fleck, O. (2001) Role of the DNA Repair Nucleases Rad13, Rad2 and Uve1 of Schizosaccharomyces pombe in Mismatch Correction. Journal of Molecular Biology, 313, 241-253. http://dx.doi.org/10.1006/jmbi.2001.5054

[30] Osman, F., Bjørås, M., Alseth, I., Morland, I., McCready, S., Seeberg, E. and Tsaneva, I. (2003) A New Schizosaccharomyces pombe Base Excision Repair Mutant, nth1, Reveals Overlapping Pathways for Repair of DNA Base Damage. Molecular Microbiology, 48, 465-480. http://dx.doi.org/10.1046/j.1365-2958.2003.03440.x

[31] Kanamitsu, K. and Ikeda, S. (2011) Fission Yeast Homologs of Human XPC and CSB, rhp41 and rhp26, Are Involved in Transcription-Coupled Repair of Methyl Methanesulfonate-Induced DNA Damage. Genes \& Genetic Systems, 86, 83-91. http://dx.doi.org/10.1266/ggs.86.83 
[32] Bähler, J., Wu, J.Q., Longtine, M.S., Shah, N.G., McKenzie 3rd, A., Steever, A.B., Wach, A., Philippsen, P. and Pringle, J.R. (1998) Heterologous Modules for Efficient and Versatile PCR-Based Gene Targeting in Schizosaccharomyces pombe. Yeast, 14, 943-951. http://dx.doi.org/10.1002/(SICI)1097-0061(199807)14:10<943::AID-YEA292>3.0.CO;2-Y

[33] Lafuente, M.J., Petit, T. and Gancedo, C. (1997) A Series of Vectors to Construct lacZ Fusions for the Study of Gene Expression in Schizosaccharomyces pombe. FEBS Letters, 420, 39-42. http://dx.doi.org/10.1016/S0014-5793(97)01486-5

[34] McCready, S.J., Osman, F. and Yasui, A. (2000) Repair of UV Damage in the Fission Yeast Schizosaccharomyces pombe. Mutation Research, 451, 197-210. http://dx.doi.org/10.1016/S0027-5107(00)00050-6

[35] Tanihigashi, H., Yamada, A., Igawa, E. and Ikeda, S. (2006) The Role of Schizosaccharomyces pombe DNA Repair Enzymes Apn1p and Uve1p in the Base Excision Repair of Apurinic/Apyrimidinic Sites. Biochemistry and Biophysics Research Communications, 347, 889-894. http://dx.doi.org/10.1016/j.bbrc.2006.06.191

[36] Hayatsu, H. (1976) Bisulfite Modification of Nucleic Acids and Their Constituents. Progress in Nucleic Acid Research and Molecular Biology, 16, 75-124. http://dx.doi.org/10.1016/S0079-6603(08)60756-4

[37] Elder, R.T., Zhu, X., Priet, S., Chen, M., Yu, M., Navarro, J.M., Sire, J. and Zhao, Y. (2003) A Fission Yeast Homologue of the Human Uracil-DNA-Glycosylase and Their Roles in Causing DNA Damage after Overexpression. Biochemistry and Biophysics Research Communications, 306, 693-700. http://dx.doi.org/10.1016/S0006-291X(03)01036-2

[38] Ikeda, M., Ikeda, R. and Ikeda, S. (2009) Spontaneous Mutation in Uracil DNA Gkycosylase-Deficient Cells of a Fission Yeast Schizosaccharomyces pombe. Current Topics in Biochemical Research, 11, 55-60.

[39] Pascucci, B., D’Errico, M., Parlanti, E., Giovannini, S. and Dogliotti, E. (2011) Role of Nucleotide Excision Repair Proteins in Oxidative DNA Damage Repair: An Updating. Biochemistry (Moscow), 76, 4-15. http://dx.doi.org/10.1134/S0006297911010032

[40] Shimizu, Y., Iwai, S., Hanaoka, F. and Sugasawa, K. (2003) Xeroderma Pigmentosum Group C Protein Interacts Physically and Functionally with Thymine DNA Glycosylase. The EMBO Journal, 22, 164-173. http://dx.doi.org/10.1093/emboj/cdg016

[41] Miao, F., Bouziane, M., Dammann, R., Masutani, C., Hanaoka, F., Pfeifer, G. and O’Connor, T.R. (2000) 3-Methyladenine-DNA Glycosylase (MPG Protein) Interacts with Human RAD23 Proteins. The Journal of Biological Chemistry, 275, 28433-28438. http://dx.doi.org/10.1074/jbc.M001064200

[42] Shimizu, Y., Uchimura, Y., Dohmae, N., Saitoh, H., Hanaoka, F. and Sugasawa, K. (2010) Stimulation of DNA Glycosylase Activities by XPC Protein Complex: Roles of Protein-Protein Interactions. Journal of Nucleic Acids, 2010, Article ID: 805698.

[43] Huang, J.C., Hsu, D.S., Kazantsev, A. and Sancar, A. (1994) Substrate Spectrum of Human Excinuclease: Repair of Abasic Sites, Methylated Bases, Mismatches, and Bulky Adducts. Proceedings of the National Academy of Sciences of the United States of America, 91, 12213-12217. http://dx.doi.org/10.1073/pnas.91.25.12213

[44] Tubbs, J.L., Latypov, V., Kanugula, S., Butt, A., Melikishvili, M., Kraehenbuehl, R., Fleck, O., Marriott, A., Watson, A.J., Verbeek, B., McGown, G., Thorncroft, M., Santibanez-Koref, M.F., Millington, C., Arvai, A.S., Kroeger, M.D., Peterson, L.A., Williams, D.M., Fried, M.G., Margison, G.P., Pegg, A.E. and Tainer, J.A. (2009) Flipping of Alkylated DNA Damage Bridges Base and Nucleotide Excision Repair. Nature, 459, 808-813. http://dx.doi.org/10.1038/nature08076

[45] Wittschieben, B.Ø., Iwai, S. and Wood, R.D. (2005) DDB1-DDB2 (Xeroderma Pigmentosum Group E) Protein Complex Recognizes a Cyclobutane Pyrimidine Dimer, Mismatches, Apurinic/Apyrimidinic Sites, and Compound Lesions in DNA. The Journal of Biological Chemistry, 280, 39982-39989. http://dx.doi.org/10.1074/jbc.M507854200 